Printed in Great Britain

\title{
ELECTRON MICROSCOPICAL OBSERVATIONS \\ ON A VERY SMALL FLAGELLATE: THE PROBLEM OF CHROMULINA PUSILLA BUTCHER
}

\author{
By IRENe MANTon \\ Botany Department, Leeds University
}

(Plates I-X)

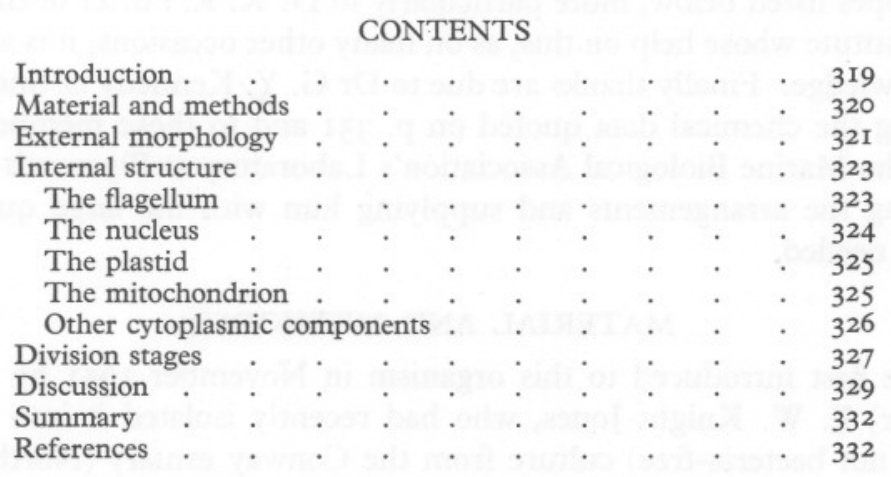

\section{INTRODUCTION}

The marine plankton flagellate hitherto known as Chromulina pusilla Butcher is one of the smallest of algal cells, being of bacterial dimensions (I-I. $5 \mu$, Butcher, 1952). For this reason it had seemed of interest to investigate its structure with the electron microscope as part of a general programme on ciliated cells in plants which has been in progress for some years. It soon became apparent, however, that there were more points of importance than had been expected at the outset. In particular the anatomical findings showed that the formal taxonomic description based on the light microscope was not only incomplete (an unavoidable consequence of the very small size), but that, as a further consequence of these physical limitations, it contained some rather fundamental misconceptions regarding the taxonomic position of the organism. By the kindness of correspondents and collaborators it was fortunately possible at once to follow up the anatomical evidence biochemically, and the combined data make the conclusion unavoidable that this organism is not a member of the Chrysophyceae (to which group the genus Chromulina properly belongs) but that its affinities lie in or near the Chlorophyceae. This naturally raises some difficult nomenclatural questions which cannot all be 
immediately resolved. The anatomical facts for this particular species are not, however, in themselves dependent on nomenclature, and since this organism is not merely an electron microscopical curiosity but is also exceedingly abundant ${ }^{1}$ in coastal waters near the British Isles, it is perhaps of some value to students of plankton that they should be made available.

I am indebted to my former technical assistant $\mathrm{Mr} \mathrm{B}$. Clarke for carrying out all the work involving shadow-cast whole mounts for external morphology, including the taking of the first four micrographs assembled on Pl. I, and also for photographic help with all the remaining Plates. As donors of material I have to thank Prof. E. W. Knight-Jones in the first instance and Dr M. Parke more recently. I am greatly indebted to the owners of the various microscopes listed below, more particularly to Dr K. R. Porter of the Rockefeller Institute whose help on this, as on many other occasions, it is a pleasure to acknowledge. Finally thanks are due to Dr G. Y. Kennedy of Sheffield for providing the chemical data quoted on p. $33 \mathrm{I}$ and to those members of the staff of the Marine Biological Association's Laboratory at Plymouth involved in making the arrangements and supplying him with the large quantity of material needed.

\section{MATERIAL AND METHODS}

We were first introduced to this organism in November I95I by $\mathrm{Dr}$ (now Professor) E. W. Knight-Jones, who had recently isolated it into uni-algal (though not bacteria-free) culture from the Conway estuary (North Wales). We made some preliminary observations on external morphology, the only aspect of structure for which adequate electron microscopical techniques existed at that date, using shadowcast whole mounts of cells killed with osmic vapour directly on to formvar-coated carriers. This isolate had supplied the type material described taxonomically by Butcher (1952) and it was also sent to us again in 1953 from Plymouth as 'flagellate 90'. At the request of Dr M. Parke we made some comparative observations on 'flagellate 90' and a new isolation known as 'flagellate 27 ' obtained by her from the English Channel which proved to be indistinguishable. Finally a third isolation, made by DrR. W. Butcher ' in June 1954 from the Thames estuary off Sheerness, Isle of Sheppey, salinity $32 \%$ at the surface' (Butcher personal communication), was received from Plymouth in 1956 and subsequently, as 'flagellate $90 a$ '. Our information on external morphology thus relates to material of unim-

\footnotetext{
${ }^{1}$ Preliminary information on the relative abundance of this organism in estuarine and coastal waters on various parts of the British coasts is given by Knight-Jones (I95I) and Knight-Jones \& Walne (I95I), but it may be of interest to quote a personal statement made by letter to the author by Professor Knight-Jones in September I958: 'I can sum up by saying that Chromulina pusilla was the most abundant organism which I observed and it occurred in the majority of the samples of full salinity sea water, both from enclosed waters and the open sea.'
} 
peachable authenticity from three different parts of the British coast, namely, Conway estuary (type culture for Chromulina pusilla, Plymouth no. 90), Thames estuary (Plymouth no. 90a) and English Channel (Plymouth no. 27).

For the anatomical investigation only flagellates 27 and $90 a$ in the Plymouth collection have been used, both supplied to us as required, by $\operatorname{Dr} \mathrm{M}$. Parke. Both cultures have been embedded and sectioned several times during 1957 and 1958 but they are so similar that it has not been felt necessary to distinguish them individually in recording the results. Pls. II, III, and V-VIII are of flagellate 27 and Pl. IV, IX and X are of flagellate $90 a$.

The technical processes involved in embedding and also for whole mounts are now standard and need not be quoted in detail. The fixative was $\mathrm{I} \%$ osmium tetroxide buffered with acetate veronal to $\mathrm{pH} 7$. All sections were cut in Leeds on a Porter Blum Sorval microtome using a glass knife and they were mounted on carbon films.

Several different microscopes have been used. For external morphology of shadow-cast material, the old Philips microscope in the Leeds Botany Department has been used and is adequate. All sections, however, have been examined on a Siemens microscope. The work was begun on the instrument in the Aeon Laboratories, near Egham, Surrey, during occasional visits in the summer of 1957. It was continued on the Siemens microscope in the Rockefeller Institute, New York, which was made available to me for two weeks at the end of December 1957. Finally it was completed on a similar instrument recently installed in the Leeds Botany Department by means of a grant from the Rockefeller Foundation.

With regard to the chemical data communicated by Dr G. Y. Kennedy of Sheffield, the methods used for the study of the pigments were a modification of those of Willstädter and Stoll I9I3, the details of which are being published by Kennedy \& Nicol (in the press).

\section{EXTERNAL MORPHOLOGY}

The first three figures on Pl. I show all that can easily be seen about the external morphology of the swimming cells by a study of whole mounts. Figs. I and 2 represent two of the strains used, at different magnifications. Both cultures are a mixture of the organism and numerous bacteria which occur with it in any field of view. In comparison with the bacteria present, the cells of the flagellate are larger (though not greatly so) and more asymmetrical. When undistorted they are more or less pear-shaped, with a laterally attached flagellum composed of two parts, namely a proximal wider portion of rather less than $\mathrm{I} \mu$ in length and a much more slender distal portion of $2-3 \mu$ long; the lengths of both parts are nevertheless somewhat variable, a matter no doubt associated with changes consequent on the growth cycle (see p. 328). 
Apart from the general shape the only other features which can be detected on whole mounts are the striations which run longitudinally down the wider portion of the flagellum and which we now know to be caused by the longitudinally running fibres inside. These striations are just perceptible in the original photograph of the left hand cell in Fig. I and again in the more highly magnified flagellum of Fig. 3. Outside the striated portion in Fig. 3 there are faint signs of a covering membrane and the distal tip of the slender extremity ends bluntly.

\section{Explanation of Plates I-IV}

Chromulina pusilla Butcher

I

Fig. I. Shadow-cast whole mount of flagellate 90 in the Plymouth collection, prepared in 1953 and re-examined in 1957 with the Philips microscope, showing 2 cells of the organism together with bacteria; this material was a direct descendant from the type culture used by Butcher 1952 and originally isolated from the Conway estuary by Knight-Jones. Micrograph M 575.4, magnification $\times$ 10,000.

Fig. 2. A cell and bacteria from a culture of flagellate 27 in the Plymouth collection, isolated by $\mathrm{Dr}$ M. Parke from the English Channel. Micrograph $\mathrm{M}_{514} \mathbf{1}_{4}$, magnification $\times$ c. 20,000 . Fig. 3. The flagellum of a cell of flagellate 90 more highly magnified. Micrograph $M_{575 \cdot 19 \times}$ c. 30,000 .

Fig. 4. A section through a cell of flagellate 27 showing the two parts of the flagellum and internal cell contents which include the plastid and pyrenoid with a part of the nucleus. Micrograph MS $56 \times 35,000$.

\section{II}

Fig. 5. A section showing the plastid with covering membrane, lamellae and pyrenoid $(P)$; part of the nucleus $(N)$ and cytoplasmic vesicles. Micrograph MS $17, \times c .50,000$.

Fig. 6. A longitudinal section to show the relative positions of the nucleus $(N)$, plastid $(P)$, fat body and flagellum. Micrograph MS 6r, x c. 30,000.

Fig. 7. Longitudinal section (lower cell) to show the positions of the mitochondrion $(m)$, plastid (c) and golgi vesicles $(x x)$, relative to the flagellum. Micrograph MS $30, c .55,000$.

\section{III}

Fig. 8. Longitudinal section showing the flagellar base $(f b)$ and arrangement of fibres in the flagellar axis, including the hair-point. Micrograph MS $220 \times$ c. 40,000 .

Fig. 9. General view of the cell shown at a higher magnification in Fig. 10. Micrograph MS $288 \times 18,000$.

Fig. Io. Part of the cell of Fig. 9 more highly magnified to show the three-layered structure of the membrane covering the hair-point and other details of the arrangement of fibres within the flagellum; the nucleus $(N)$, perinuclear space $(p s)$, a bacterium in section $(B)$. Micrograph MS 29I, $\times 100,000$.

\section{IV}

Fig. Ir. A cell showing among other features the flagellum, the nucleus $(N)$, the mitochondrion in TS $(m)$, vesicles $(v)$ not part of the peri-nuclear space $(p s)$, the plastid with central pyrenoid $(P)$, two peripheral small spherical bodies within the plastid and the array of parallel curved membranes near to the plastid surface and joined in pairs at intervals. Micrograph H I237 × 90,000. 


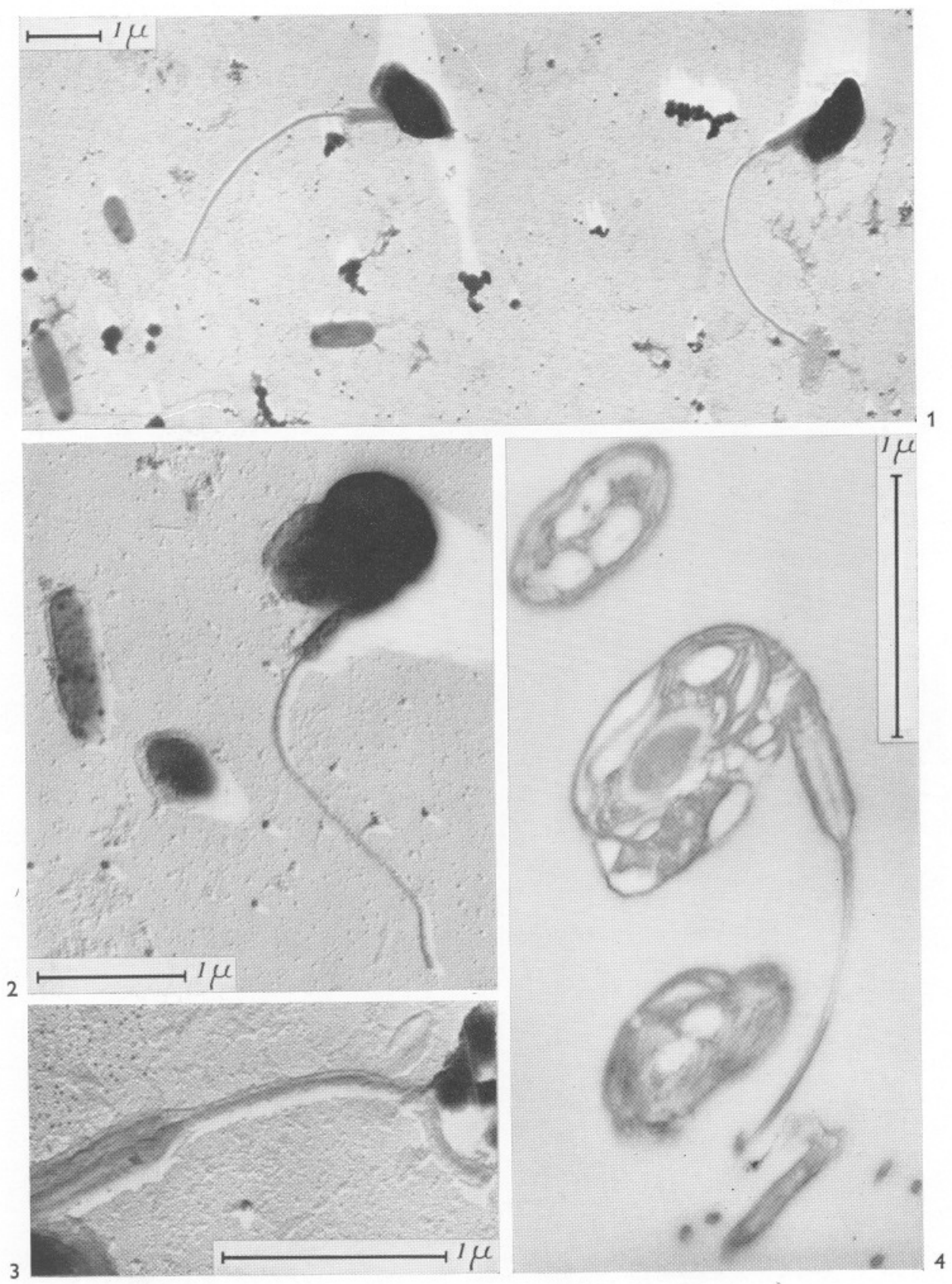

(Facing p. 322) 

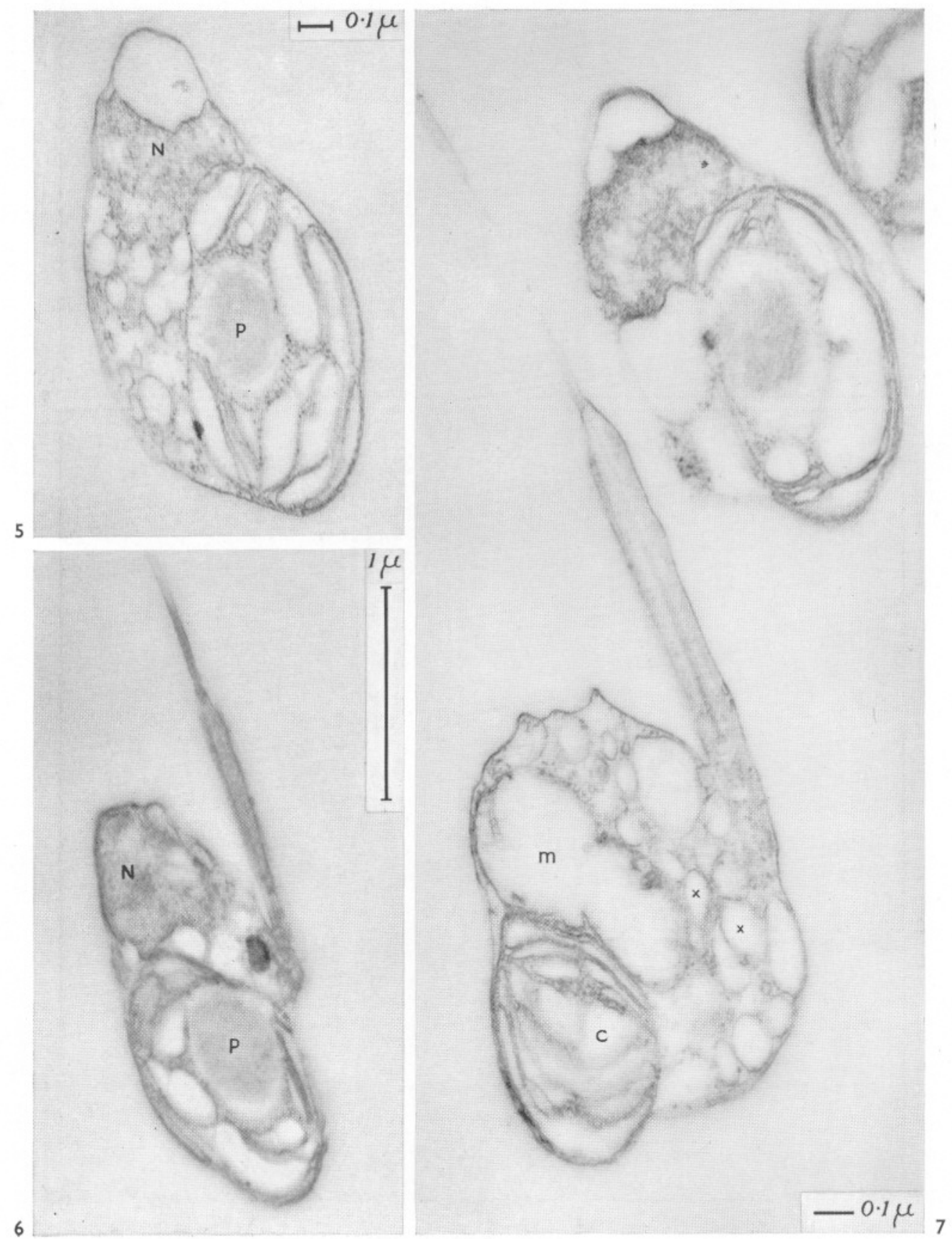

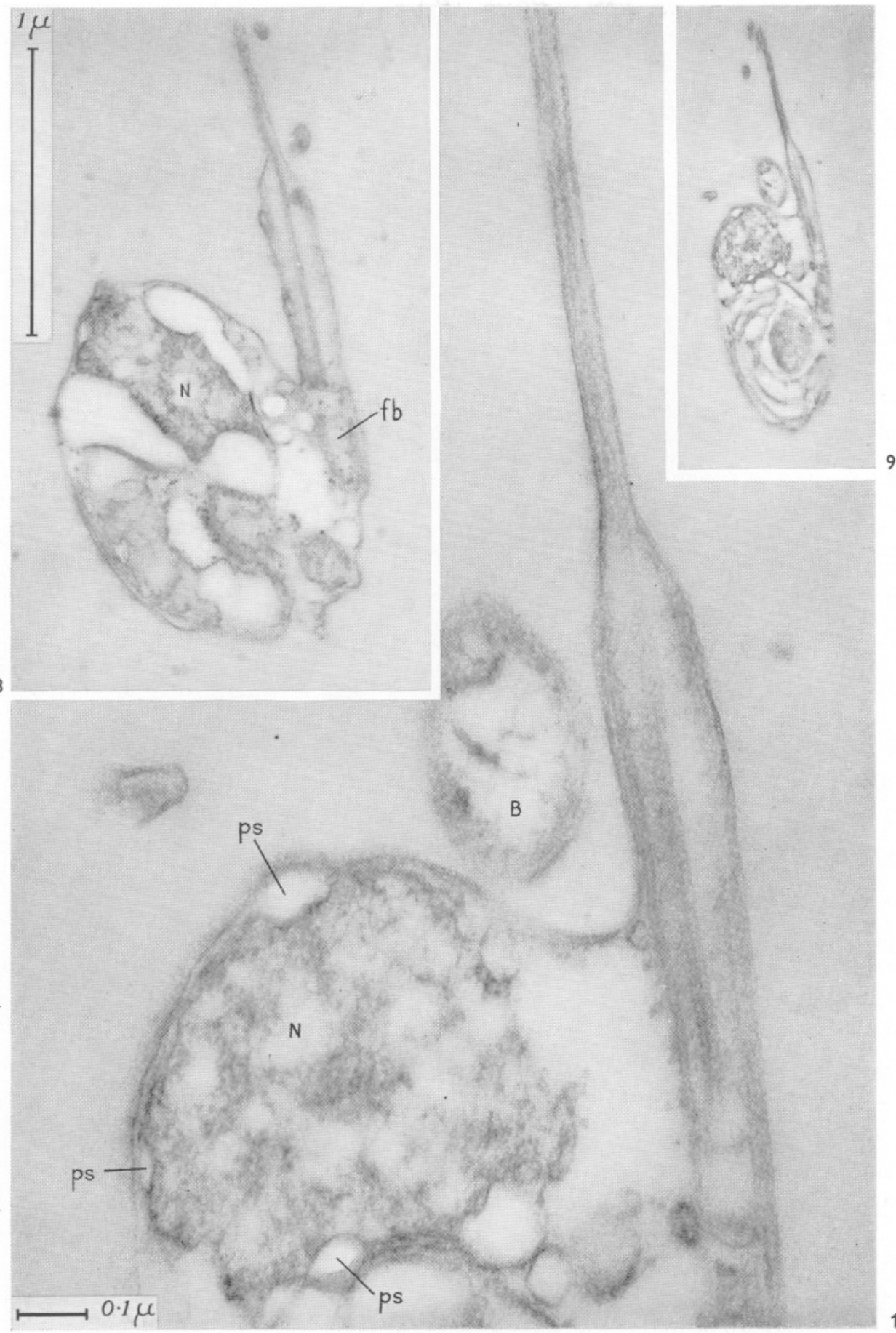


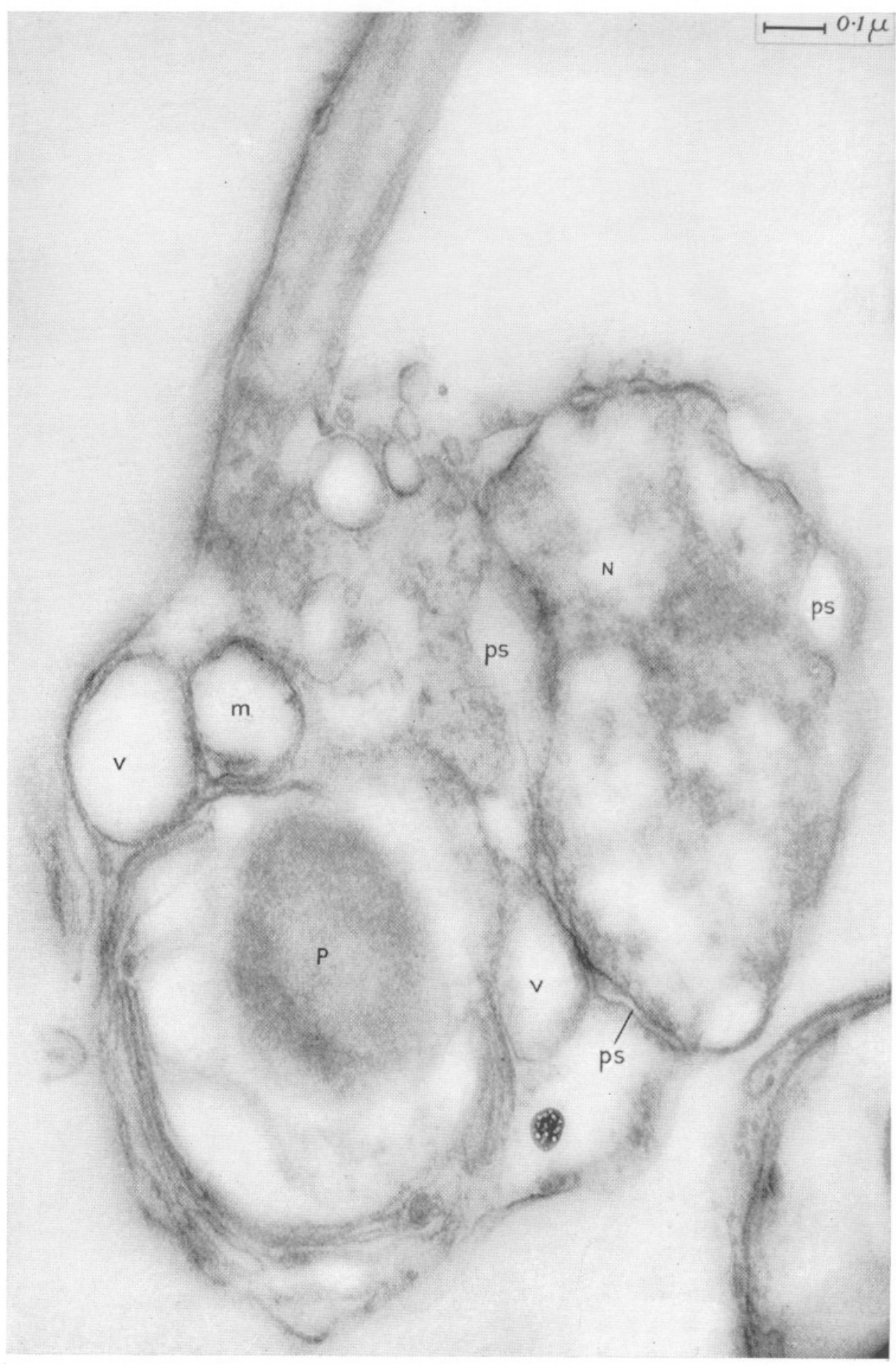




\section{The flagellum}

\section{INTERNAL STRUCTURE}

The first object of enquiry was the internal structure of the two parts of the flagellum since the distal portion is so slender that it seemed unlikely that it could contain the normal $9+2$ internal fibres so characteristic of cilia and flagella in plants and animals generally, while the fatter basal part, when first seen, could have been interpreted as a sheath, and this, had it been confirmed, would have been a character of major classificatory importance.

A glance at any of the longitudinal sections included in Pls. I-III is sufficient to dispel any suggestion that the thickening of the base of the flagellum is due to a sheath. The entire surface of both parts is smoothly covered by a membrane which is continuous with the body membrane and, like it, is threelayered, being composed of two electron dense surface layers separated by a translucent central layer. This structure is most clearly demonstrated in the distal extremity of the flagellum shown at a magnification of $\times 100,000$ in Fig. IO, Pl. III, which also shows the smooth tapering which is the only external mark of the transition region between the two parts of the flagellum.

Transverse sections of the basal part of the flagellum appear incidentally in many of the illustrations but most clearly in Plate VI. These show unmistakably that in this region the surface membrane closely covers the normal array of $9+2$ strands, among which the outer 9 are double with the plane of separation of half-strands arranged radially. There is therefore nothing peculiar about this part of the flagellum except its extreme shortness.

The structure of the distal region is more difficult to investigate directly for obvious reasons. Transverse sections of it are so small that it is only by accident that one suitably orientated and of sufficient thinness to show internal structure is recorded at a magnification high enough to be of use. One such is however included in Fig. I5, Pl. VI, and if the evidence from this is amplified by comparison with longitudinal views, more especially those of Fig. 8, Pl. III, and Fig. I7, Pl. VII, the general features can be ascertained with reasonable certainty. Within the bounding triple-membrane there seems to be a core composed mainly of prolongations from the two central strands of the basal part of the flagellum, but with little or no contribution from the 9 peripheral strands. The structure is thus not that of a complete flagellum but seems to correspond more to a specialized and exceptionally elongated distal hair-point. Whether or not this hair-point is self-motile or passively dependent on motion transferred from the flagellum proper cannot be directly ascertained, but the apparent simplicity of its structure suggests the latter.

At the base of the flagellum, and separated from it by a transverse diaphragm, there is a normal type of basal body within the cell. The diaphragm is sometimes exactly level with the cell surface, e.g. Fig. 8, Pl. III, but is sometimes much more deeply seated (Fig. 9, P1. III), a difference of position which 
must also be connected with the growth cycle and which will be further discussed below (p. 329). When seen in transverse section (Fig. I4, Pl. VI, fb, right hand cell) the basal body appears hollow, with a wall composed of 9 peripheral fibres but with no central ones and no separate covering membrane. These are all normal features of flagellar basal bodies.

\section{The nucleus}

This is not the most conspicuous organ of the cell but is conveniently dealt with next. It can be seen at a high magnification in Figs. Io and II (Pl. III and IV), after which it will be readily recognized in other parts of many of the remaining plates. The nucleus is somewhat laterally situated within the cell; there is little ascertainable internal structure except a somewhat diffuse nucleolus. (See especially Fig. I $2 c$ and $d, \mathrm{Pl}$. V.)

The nuclear membrane is almost certainly of the usual type though these small cells are ill adapted for clear demonstration of the finer details owing to the strong curvature of the nuclear surface and the difficulty of detecting suitably cut cells. Signs of the perinuclear space bridged at intervals are nevertheless detectable in sections such as those of Figs. IO and II, though the extremely large size of certain spaces abutting on the nucleus in other sections (e.g. at one end of the nucleus in Fig. I2, Pl. V, and at both ends in Fig. 13) may be artificial distortions due to stretching of the space and local collapse of the nucleus during the processes involved in embedding.

We have been unable to trace any fibrous or other connexions between the nucleus and the flagellum.

\section{Explanation of Plates $\mathrm{V}$ and VI \\ Chromulina pusilla Butcher \\ V}

Fig. I2a-e. Series of consecutive sections through a cell passing through the nucleus $(N)$, mitochondrion $(m)$, plastid with central pyrenoid $(P)$ and peripheral plastid lamellae somewhat distorted by the fixative, a fat body and part of the perinuclear space ( $p s)$ probably artificially stretched as a fixation artefact. Micrographs RS 162, 161, 160, 158, 157, Xc. 43,000.

Fig. 13a-c. Three consecutive sections through part of another cell to show curvature of mitochondrial cristae; nucleus $(N)$, mitochondrion $(m)$. Micrographs RS 158, 160, 162, $\times$ c. 43,000 .

\section{VI}

Fig. 14. Two cells in transverse section showing the different parts of the flagellum within the cytoplasm; $f b$ (right-hand cell) a basal body in TS; $y f$ (left-hand cell) axis of a young flagellum which has not yet emerged from the cytoplasm; nucleus $(N)$, plastid with pyrenoid $(P)$. For further explanation see p. 329. Micrograph RS $445 \times c .55,000$.

Fig. I5. TS of a flagellar tip showing contents; for further description see text p. 323. Micrograph MS $298 \times$ roo,000.

Fig. I6. TS through a cell somewhat flattened by a knife, showing details of the mitochondrion $(m)$, flagellar axis, and paired lamellae in the plastid $(P)$; arrows point to places where the triple structure of the surface membrane is resolved. Micrograph MS 242, $\times 55,000$. 


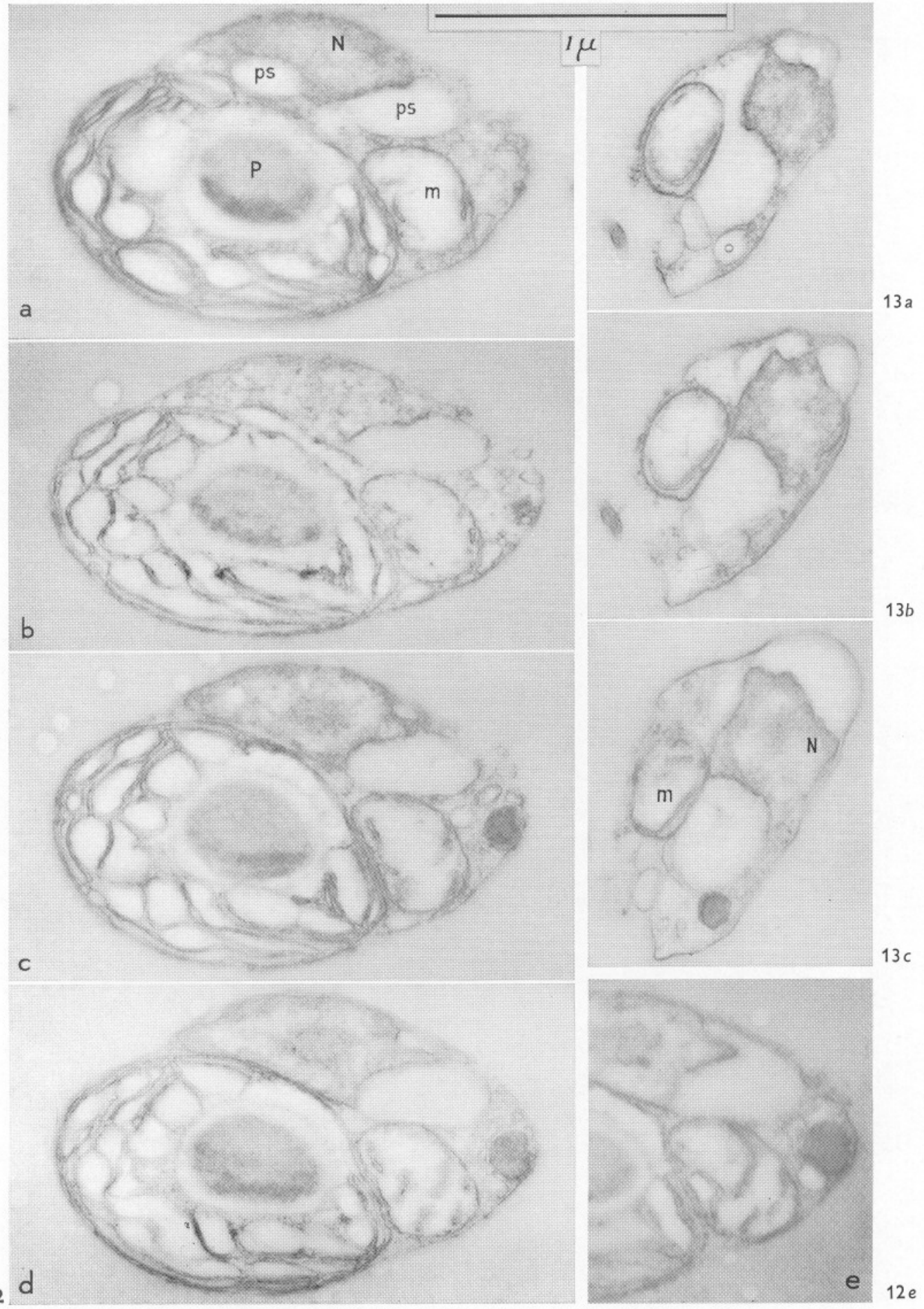

(Facing p. 324) 


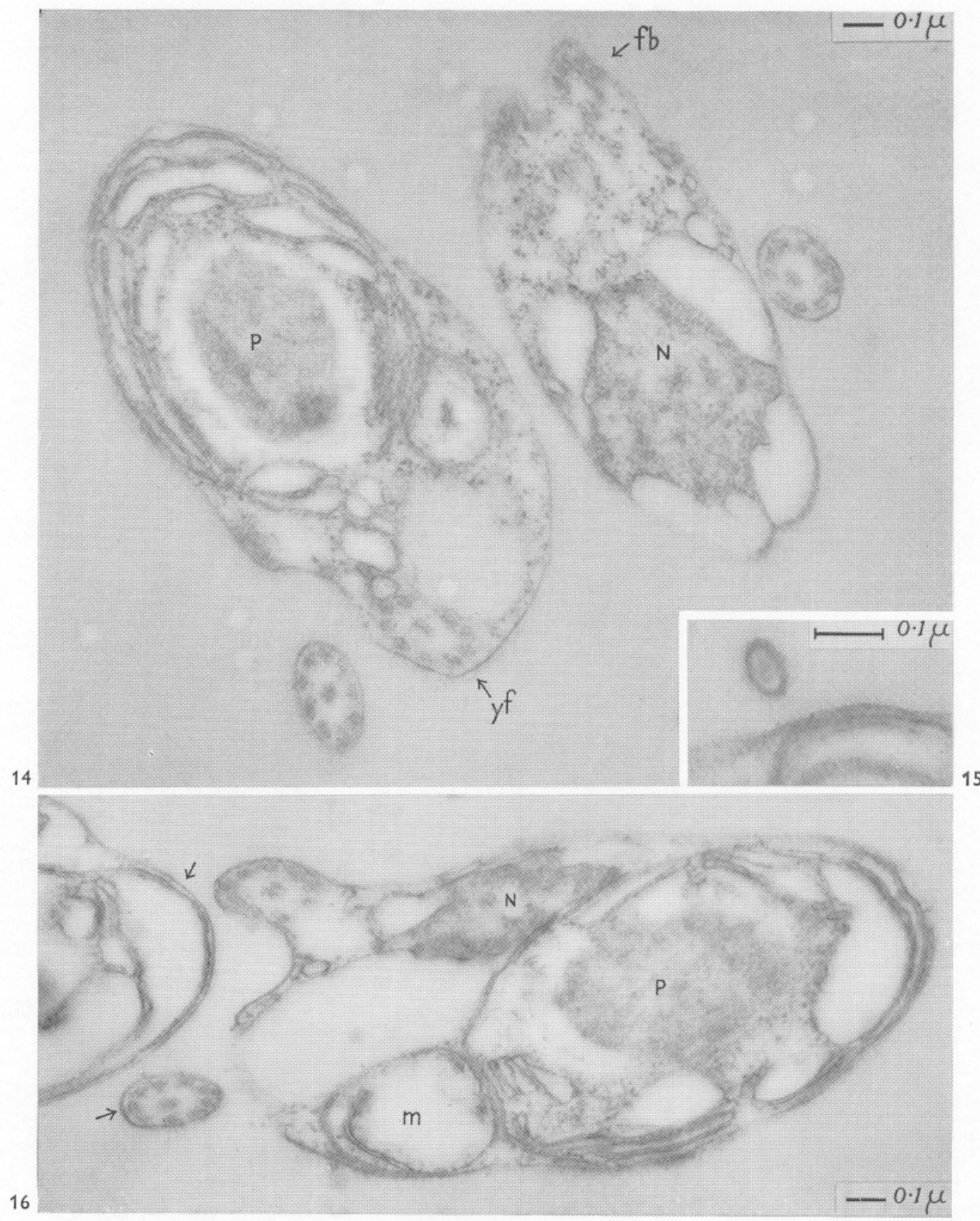




\section{The plastid}

This is by far the largest organ in the cell, and the most conspicuous part of it is the central pyrenoid which is large enough to be traversed by and to dominate almost every type of section except extremely tangential ones, as may be seen in some part of each of Pls. I-X.

There is as yet no chemical knowledge about the nature of the photosynthetic product except that tests for starch with iodine are invariably negative. No suggestions can therefore be made about the chemical nature of the dark central body forming the core of the pyrenoid and which may be expected to be the main food reserve. Outside this central dark area is a narrow lighter layer (well seen in Fig. I2c, Pl. V, and elsewhere), outside which is granular material which seems to be part of the normal ground substance between the outer lamellae and which, in small bands, can be encountered at all levels out to the plastid surface (see especially Fig. 5, Pl. II). The plastid surface itself is bounded by a membrane (Fig. 5 and elsewhere) and between this and the pyrenoid are a series of curved membranes joined in pairs at their edges (see especially Figs. II, 16, 23, etc.). The enclosed spaces within each membrane pair are often distorted into lenticular blisters by the action of the fixative (e.g. Fig. 12 and elsewhere), though in more fortunately fixed specimens the array of membranes lie more evenly parallel to each other (Fig. II, Pl. IV) in a crescentic path. They do not, however, extend without interruption over the entire circumference of the plastid, some points of interruption being related to the presence of small vesicles of unknown nature (Fig. II); other points of interruption, which are not detectably so related are also visible in Fig. II and elsewhere (see for example Fig. 23, Pl. IX).

This arrangement of lamellae, which is difficult to describe verbally, but which will perhaps become sufficiently clear by further scrutiny of Pls. II, IV, $\mathrm{V}$ and VI, is quite unlike that of the Chrysophyceae for which preliminary reports from our own experience are available for Synura (see Manton, 1955) and for Chrysochromulina (see Parke, Manton \& Clarke, 1958, 1959). It is, however, not unlike that recently described for Chlamydomonas by Sager \& Palade (1957), allowance being made for the difference of size. This was therefore the first reason to suspect that this organism had been wrongly placed.

\section{The mitochondrion}

A second reason for suspecting a classificatory error was the fine structure of the single mitochondrion which is always to be found as a sausage-shaped organelle (round in cross-section) in close contact with both plastid and nucleus and not far removed from the base of the flagellum. It may be seen, and is labelled, in Fig. 7, Pl. II, Fig. II, P1. IV, both series on P1. V, and elsewhere. The normal mitochondrial structure in all members of the Chrysophyceae, Phaeophyceae, and Xanthophyceae investigated so 
far $^{1}$ shows an array of closely crowded tubular villi extending from the inside of the mitochondrial wall into the cavity and corresponding to the 'cristae' of most animal mitochondria (Palade, 1952, et seq.). In Chlamydomonas, however the mitochondria are described (Sager \& Palade, 1957) as having a few, widely separated flattened cristae which scarcely interrupt the central lumen. Had this description not appeared as the present enquiry was being carried out we might have been in some doubt as to the true identity of our organelle. As it is the figures cited above, especially the two series of sections contained in P1. V, and more highly magnified single views such as that of Fig. I6, Pl. VI, leave no doubt that this organ is not only a mitochondrion but a mitochondrion of the chlorophycean but not chrysophycean type.

Peculiar features are the facts that the organelle is single and that the cristae are often curved. The first observation will be discussed again in the section on cell division (p. 327). Curvature of the mitochondrial cristae can be seen best in Fig. I3 $a-c$, Pl. V, and in Fig. I6, Pl. VI.

\section{Other cytoplasmic components}

Near to the base of the flagellum (Fig. 6, Pl. II) there is a fat body, which once seen can be picked up in other planes of section, e.g. Figs. I2c-e. Equally close to the base of the flagellum (Fig. 4, Pl. I, Fig. 7, Pl. II, etc.) is a compact group of small vesicles which probably represents the equivalent of a golgi area $(x-x$, Fig. 7$)$. There are in addition a few other vesicles of various sizes which are not of this nature. Some good examples are contained in various parts of the cytoplasm not closely associated either with the flagellum or with the nucleus ( $v$ in Fig. II, Pl. IV) which seem unlikely to be either artifacts or other organelles.

Lastly there are granules. The amount of granular cytoplasm is very restricted. The large organelles (nucleus, plastid, mitochondrion) are so near to the cell surface on their outer sides that there is little except the body membrane to cover them. Only the angular spaces between these organs, and especially between them and the flagellar base, contain granular cytoplasm in an appreciable amount, together with vesicles of various sizes. This may be examined to advantage in Fig. 7, Pl. II, and Fig. 14, P1. VI.

Finally the body membrane already discussed in a preliminary way in connexion with the flagellum can be demonstrated independently in Fig. I6, Pl. VI (arrows) as a three-layered structure identical with that of the membrane covering the surface of the flagellum.

1 The literature on this subject is rapidly becoming too voluminous to quote in full but sample micrographs recording some of our own experience of the fine structure of mitochondria in various groups will be found in: Phaeophyceae Fucus (Manton \& Clarke, 1956), Scytosiphon (Manton, 1956); Xanthophyceae Vaucheria (Greenwood, Manton \& Clarke, 1957, Greenwood, 1959); Chrysophyceae Chrysochromulina (Parke, Manton \& Clarke, 1958, 1959). 


\section{DIVISION STAGES}

No attempt has yet been made to study nuclear division in this organism, and no stages of it other than the final stage of a binucleate cell not yet cleaved into two (Fig. I8, P1. VII) have yet been identified. Several other manifestations of cell division are however conspicuous and, since these add very greatly to our knowledge of certain structural aspects of the other organs, it is important to include at least some of them.

Several stages in the cleavage of both plastid and mitochondrion are represented in Pls. VIII-X. The plastid seems to divide first and the cleavage passes right through the pyrenoid, starting apparently as an intucking of the plastid membrane on the side towards the nucleus. Examples of completely divided plastids are contained in Fig. 20, Pl. VIII and Fig. 26, Pl. X, an important detail of the latter being the demonstration, so far the best available for this organism, that the plastid membrane is probably compound (arrows at base). Incomplete stages are contained in Figs. 22-25, Pls. IX and X. Before scrutinizing these it will perhaps be helpful to notice that whereas Figs. 24 and 25 represent two different cells cut in planes approximately at right angles, Figs. $22 a$ and $22 b$ are different sections of the same cell, Fig. $22 a$ being nearer to the cell surface than $22 b$. Finally Fig. 23, though at an uncertain magnification owing to an uncorrectable mistake in the record made at the time the micrograph was taken, is included for the completeness with which the very large plastid shows numerous areas of lamellar junction (marked by arrows) and an incipient cleavage furrow.

Three stages of cleavage of the mitochondrion are represented by Figs. 22, 26 and 2I (long arrow), the sequence being in the order of citation of the figures. As cleavage of the plastid is progressing the single mitochondrion seems to become partly drawn into the plastid cleavage furrow (Fig. 22a); it then becomes bent (Fig. 26) into a $U$ shape, finally a depression resembling a cleavage furrow appears on the concave side (Fig. $2 \mathrm{r} b$ ), by which time plastid cleavage is complete and the two halves have begun to separate. Further details regarding the final separation of the mitochondrion halves have not been traced.

Observations on the mode of origin of a new flagellum are much more difficult to make and only a few stages have so far been detected, in most cases by accidental inclusion in fields recorded for other purposes, since it is almost impossible to detect them directly with the eye on the fluorescent screen of the microscope. However, a new flagellum undoubtedly forms close to an old one and it is sometimes possible, in dividing cells, to pass through the two basal bodies side by side (Fig. I9, P1. VII). It is therefore likely that the new basal body from which the new flagellum will grow out must be formed in some structural relation to the old basal body, but what this relation is has not yet been elucidated. However, one fortunate series of sections which happened to 
lie close to the field of Fig. I4 is reproduced in Figs. I $7 a-f, \mathrm{Pl}$. VII, to illustrate a very young flagellum in an early stage of growing out. It is slightly tilted and the basal body is best seen in the lowermost of the six sections (Fig. I $f f$ ). The central strands passing out into a very short hair point are contained in Fig. $\mathbf{I} 7 d$, the tip of the short hair point itself being crossed by the path of an independent long hair point which can be seen passing obliquely through all the sections. The 9 strands of the peripheral ring are distributed among all six sections, though it should be noted that these strands are still entirely within the body membrane of the parent cell.

This observation on an undoubtedly young specimen is important for providing a clue to some of the differences in external length and in the position of the basal body relative to the surface, to which reference has been made on previous pages, especially in relation to the longitudinal sections included on Pls. II and III. It is obvious that after a new flagellum has been laid down and

\section{Explanation of Plates VII-X}

Chromulina pusilla Butcher

VII

Fig. I $7 a-f$. Series of six adjacent sections passing longitudinally through a young flagellum not yet emerged from the subtending cell. For further explanation see text. Micrographs RS 440, 44I, 442, 443, 444, 445, $\times c$. 30,000.

Fig. I8. Sections through a dividing cell showing two nuclei. Micrograph $\mathrm{H} 2278 \times 30,000$. Fig. 19. Section through a dividing cell with two ciliary bases side by side (arrows). Micrograph MS 35, ×c. 30,000 .

\section{VIII}

Fig. 20. Group of cells one of which shows a divided chloroplast. Micrograph MS 44, $\times$ c. 25,000 .

Fig. 2I $a$ and $b$. Two successive sections through a field of three cells the lowest of which contains a dividing mitochondrion (2I $b$ ) and a divided plastid (2I $a$ and $b$ ). Micrographs RS 416 and $417, \times c .25,000$.

IX

Fig. $22 a$ and $b$. Two sections (not immediately adjacent) through a dividing cell showing early stages of division of the mitochondrion (22a) and plastid (22b). Micrographs $\mathrm{H}_{2} \mathrm{II}_{3}$ and $2121, \times 30,000$.

Fig. 23. A giant cell (probably a 'double-division') to show details of an early stage of fission of the plastid, arrows indicate places of fusion of lamellae. Micrograph $\mathrm{H} 2123$, magnification uncertain but probably between 40,000 and 50,000 .

\section{$\mathrm{X}$}

Fig. 24. A cell cut transversely to the plane of flattening showing a dividing plastid in an intermediate condition. Micrograph $\mathrm{H} 2 \mathrm{I} 26 \times$ c. 30,000 .

Fig. 25. A cell at approximately the same stage as that of Fig. 24 cut in a place at right angles to that of Fig. 24. This section includes a nucleus above the dividing plastid. Micrograph $\mathrm{H} 2 \mathrm{II} 5, \times$ c. 30,000 .

Fig. 26. A cell with a divided plastid and a dividing mitochondrion $(m)$ more highly magnified to show among other details the multilayered structure of the plastid membrane (arrows). Micrograph $\mathrm{H} \mathrm{2298,} \times 80,000$. 


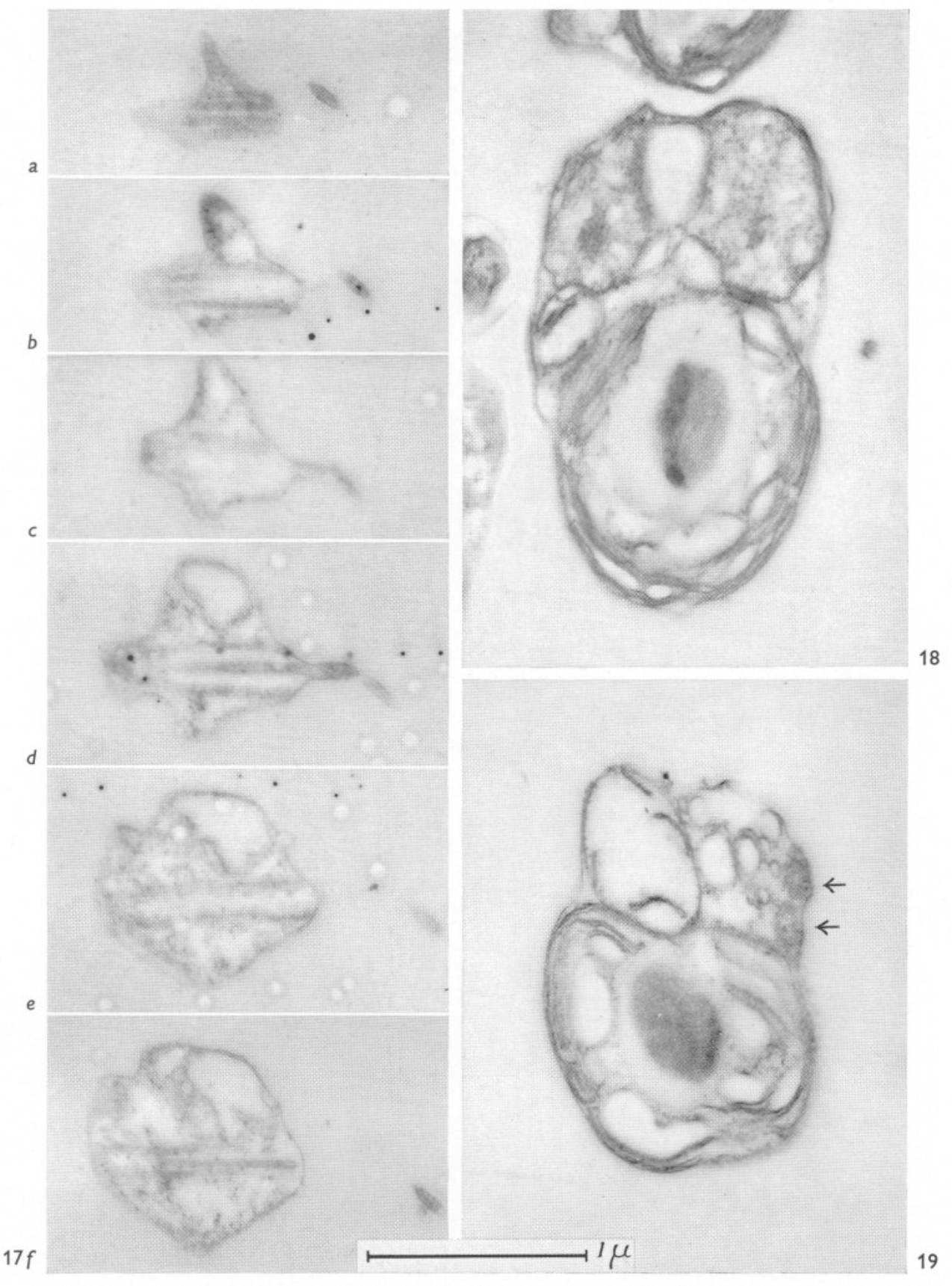

(Facing p. 328) 
J. MAR. BIoL. Ass. U.K., 38 (2)

Manton. PLATE VIII
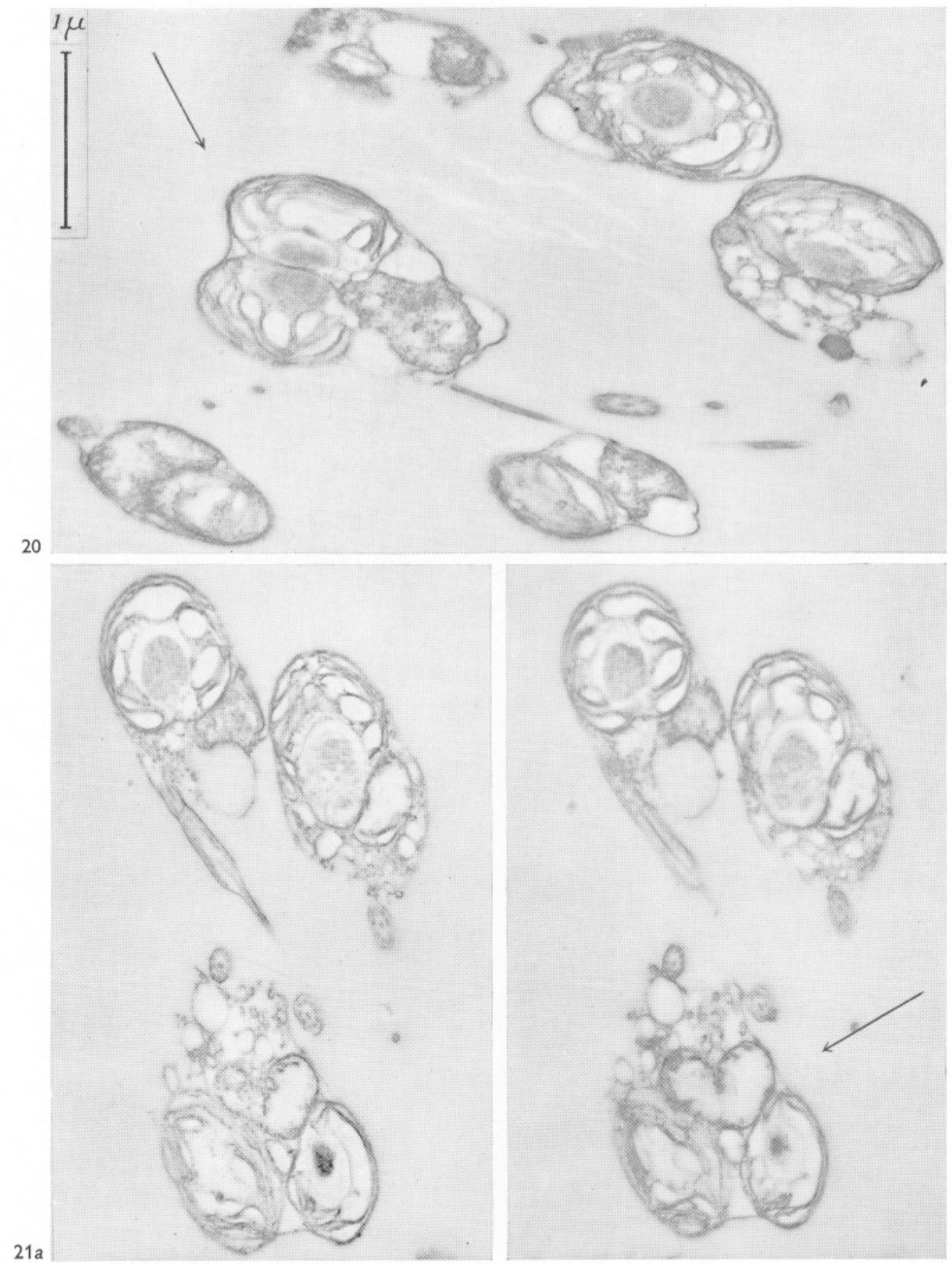

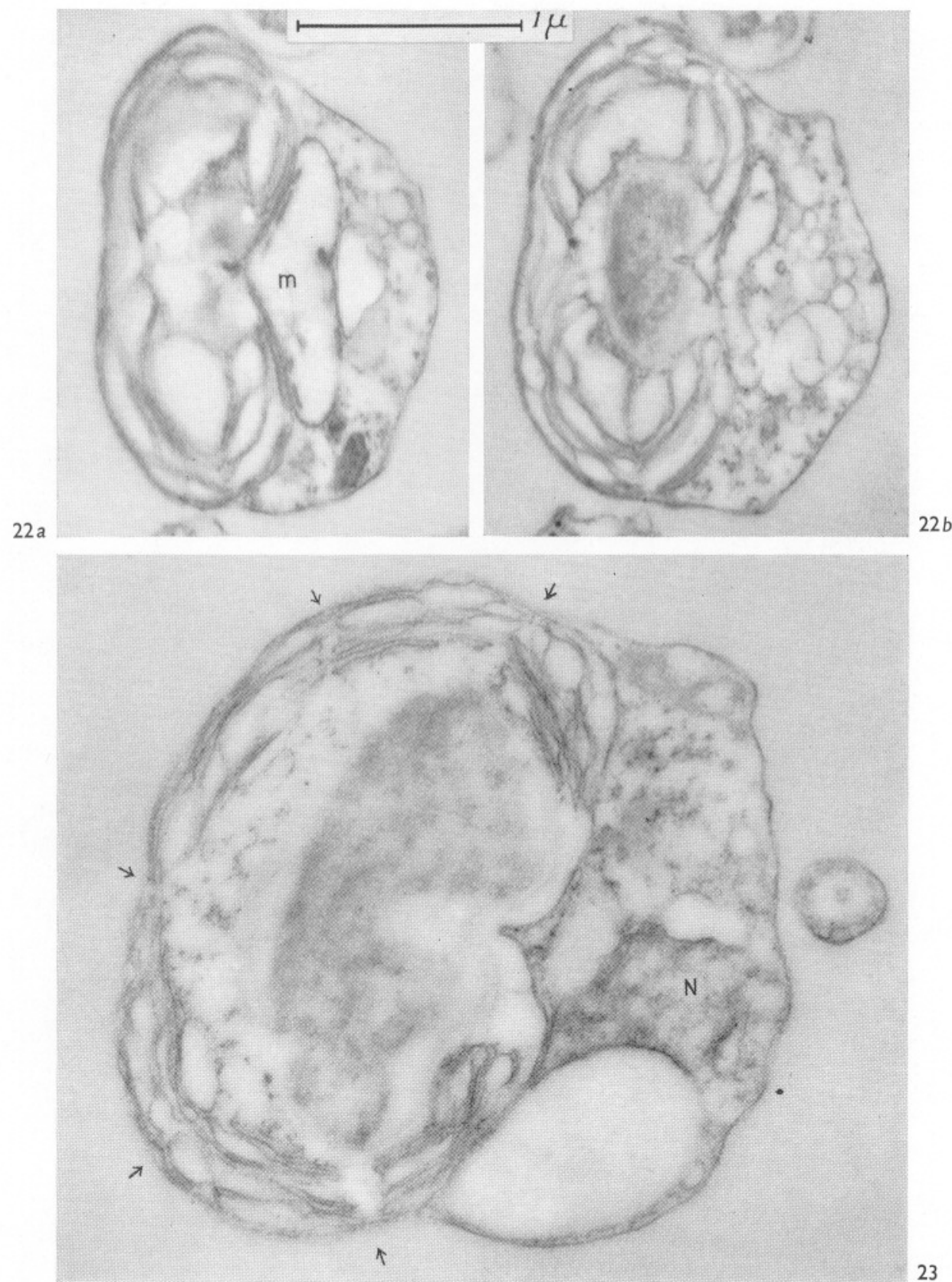

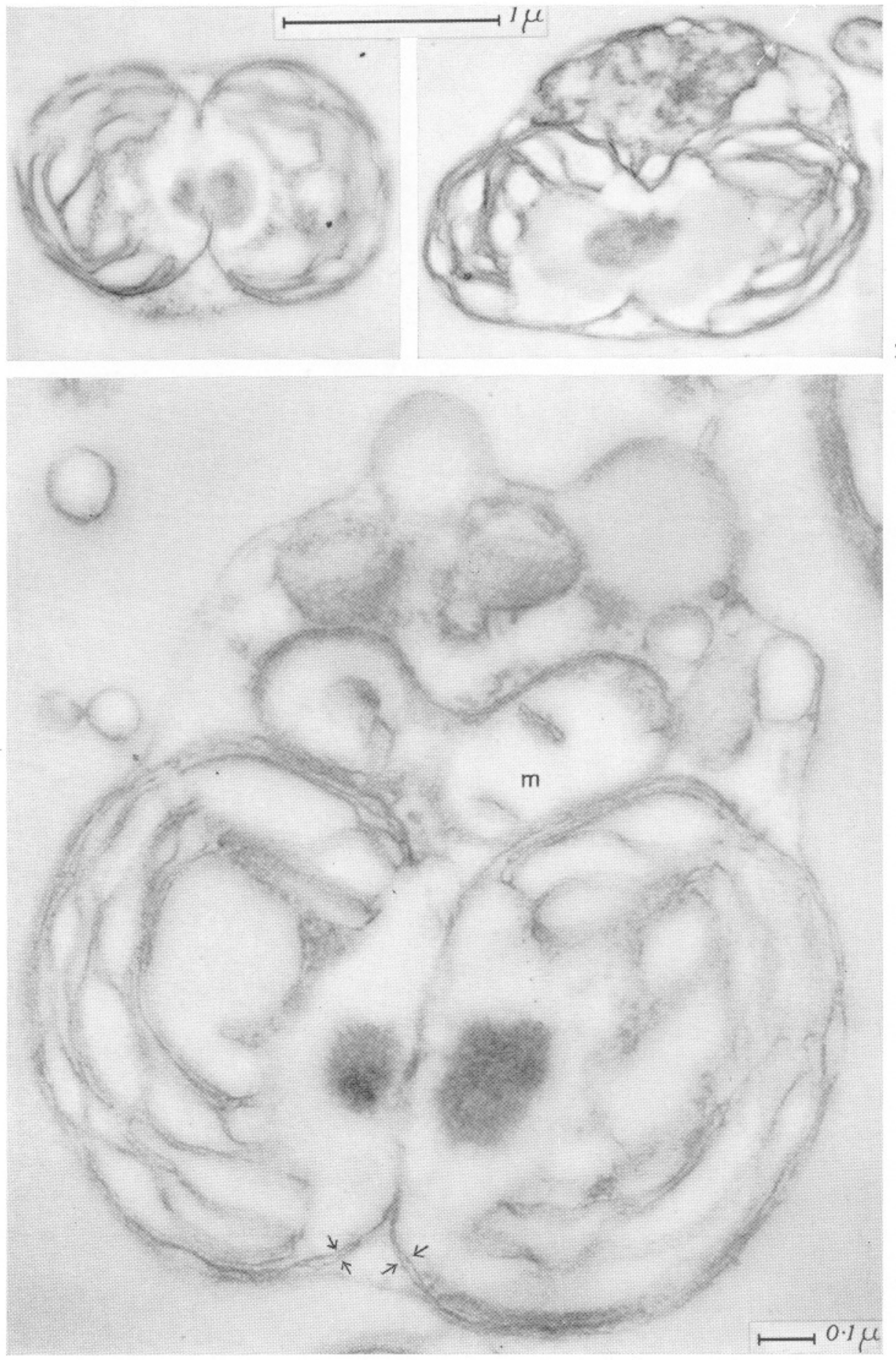
has elongated within the cell (not necessarily to its full size) there must at some point be an active movement of its basal body from a deep-seated position out to the surface, which is not true growth although externally it may resemble it. This movement could be very rapid, but until it has been completed a transverse section of a cell at a suitable level will show an internal flagellar axis without a separate membrane as in the left-hand cell of Fig. I4 $(y f), \mathrm{Pl}$. VI, while a similar section taken further out can show a partially detached flagellum as in Fig. I6, P1. VI. Comparison of both these figures with the longitudinal view of Fig. IO, Pl. III, will at once make this matter clear, and it will also be apparent by way of contrast that for any cell which had reached the condition of Fig. 8, P1. III, a transverse section at no matter what level could at most include the flagellar basal body $(\mathrm{fb}$ in the right-hand cell of Fig. 14) within the subtending cytoplasm but no part of the flagellar axis.

\section{DISCUSSION}

Ignoring for a moment the taxonomic implications of the facts presented there are several points in the structure of this curious little organism which are of potential interest to students of fine structure. The first of these is the extreme numerical reduction of all the component parts in correlation with the greatly reduced overall dimensions of the cell. By the time that a cell is restricted to one nucleus, one plastid, one mitochondrion, one little group of golgi vesicles, one fat body, one flagellum and a very small amount of residual cytoplasm, it seems doubtful whether any further reduction would be possible without involving the fundamental structure of the organelles themselves. This has however not yet occurred in this species. Qualitatively all the organelles even the greatly abbreviated flagellum, are essentially of the same type as those of other algal cells, allowance being made for minor differences in relative dimensions of which those shown by the flagellum are the most extreme. Even here, however, the flagellum is only exceptional in the extreme disproportion between the flagellum proper (the thickened base) and its hairpoint (the whiplash distal part). Hair-points are nevertheless in themselves common enough though usually short (see Manton, Clarke \& Greenwood, I955) but even long hair-points can sometimes be found, occasionally as an abnormality, as in Fucus (see Manton \& Clarke, 195I), or even sometimes perhaps as a permanent feature (see Petersen, Caram \& Hansen, I958, on Chordaria). In none of these other organisms has it been shown that the hairpoint contains a prolongation of the central strands, so that strict homology cannot yet be claimed. It is nevertheless at least possible that the exceptional condition about our present species might be not so much the permanent presence of a long-hair point as the fact that the flagellum proper is so short that it could be mistaken for a swollen base to the other organ. When this $\mathbf{I} \mu$ long basal part is recognized for what it is the transverse dimension is not 
fundamentally different from that of any other plant flagellum for which the diameter in sections is known. ${ }^{1}$

The reduction of the mitochondria to one only is a highly interesting feature for which we have no other examples at present. The observations made on cleavage, both of the plastid and the mitochondrion, suggest that in this organism both are self-propagating organelles which are not, and probably cannot be, reformed from any other cell component. For the mitochondria this has long been suspected, though in ordinary circumstances it is difficult to prove, since in a cell with many mitochondria it is usually impossible merely from the shapes to distinguish with certainty between division stages and coalescence. In this case the latter explanation of the shapes encountered seems excluded and we can only logically interpret the stages seen as reproduction by division.

For the plastid this is well known in many algae since green chromatophores are commonly quite large enough to be studied alive in considerable detail. In the lower algae of all colours other than blue-green it is a commonplace that mature plastids often divide without ever being resynthesized de novo. Nevertheless in many algae and in all or almost all higher plants the actual plastid is commonly developed not from another mature one but from a colourless primordium which alone has the capacity for division. This condition is, however, unlikely to be primitive and one may believe it not yet to have been reached by algal cells at the evolutionary level of our present flagellate.

The growth of the flagellum is a matter of considerable interest since this is a subject which, in plants, has not yet been effectively studied. Much would be learnt if it were possible to detect the first beginnings of a new flagellum. The much more limited observations made here of growth from a base inside the cell (the series of Fig. I7, Pl. VII) are nevertheless of importance in showing among other things that the flagellar membrane is not merely like the body membrane and continuous with it but is actually a part of the body surface which has been lifted up from below by growth of the flagellum itself. This could not have been deduced with certainty by observation of the mature structure, and it is a fact which will be of considerable comparative interest as knowledge of other organisms increases.

\footnotetext{
1 Exact measurements of the diameter of cilia and flagella have not been published as such nor are they easy to obtain with any accuracy owing to the distortions inseparable from the processes involved in their study. Nevertheless a rough estimate can be obtained by comparing the published micrographs of the best fixed specimens for which, when expressed as vulgar fractions to avoid falsely suggesting greater accuracy than is justified, we obtain the following:

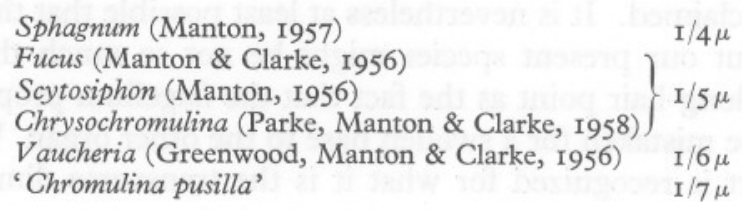


With regard to the other aspect of the investigation, namely, the taxonomic implications, it is obvious that we have here unintentionally entered a highly specialized field, of active concern to students of plankton but one which can only be effectively dealt with by an expert professional algologist, which we do not claim to be. Nevertheless the general principles are clear enough, for in addition to our own previous work on other members of the Chrysophyceae and related groups, there is a recent electron microscopical study on Chromulina psammobia by Fauré-Frémiet and Rouiller (1957) which proves beyond doubt that the anomalous characteristics of 'Chromulina pusilla' are not shared by other species more properly included in that group, and that, in addition, our species lacks several characters such as the hairy appendages on a forwardly directed flagellum which are known to exist in other species of the genus.

A conclusive piece of further evidence can moreover be quoted. By cooperation between Dr M. Parke of Plymouth and Dr G. Y. Kennedy of Sheffield a large amount of material was cultured and subjected to qualitative pigment analysis. The findings (Kennedy, personal communication dated I5 November I957) were as follows: 'present: chlorophyll $a$, chlorophyll $b$, no trace of any other chlorophyll; $\alpha$ and $\beta$ carotene, lutein; no other pigments'. The decisive factor in this list is of course chlorophyll $b$ which is entirely absent from all known representatives of the Chrysophyceae but which is virtually diagnostic of Chlorophyceae and near relatives. Its presence is the final and unequivocal proof that this organism must be removed out of the genus Chromulina and out of the class Chrysophyceae.

Whether, when this is done, it can properly be included within any existing genus of Chlorophyceae or whether indeed an entirely new group of nonstarch-producing flagellates will be required to contain it are matters on which it would be wrong at this stage to express further opinions. Dr M. Parke is actively engaged in exploring the various alternatives and may be expected to publish her findings shortly. In the meantime it may be helpful to enumerate the taxonomically significant characters which the electron microscope has revealed and which will need to be covered by any generic diagnosis which may eventually be selected. An emended description, not including any additional facts which may still be ascertainable with the light microscope, is therefore as follows:

Unicellular pigmented flagellate, of average size $c . \mathrm{I} \times \mathrm{I} \cdot 5 \mu$, possessing chlorophylls $a$ and $b$, carotenes $\alpha$ and $\beta$, and lutein, but not forming starch; with a single plastid possessing a large central pyrenoid covered by a shell of concentric paired lamellae resembling in a general way those of the Chlorophyceae; with a single mitochondrion possessing a sparse array of flattened cristae resembling those of certain green algae, notably Chlamydomonas, and with a laterally attached flagellum $c$. I $\mu$ long terminating in a slender hair-point $c .3 \mu$ long, both parts directed backwards during swimming; the body smoothly covered by a membrane but without surface scales or cell wall; multiplication by fission involving the plastid, the mitochondrion and the nucleus with the formation of a new flagellum immediately beside the old one. 


\section{SUMMARY}

The very small flagellate hitherto known as Chromulina pusilla Butcher has been examined morphologically and anatomically with the electron microscope. The cell is found to contain a nucleus, plastid, one mitochondrion, one small golgi area, one fat body, a small amount of granular and vesicular cytoplasm and a flagellum less than $\mathrm{I} \mu$ long terminating in an extended hair-point, the whole surface being covered by a three-layered membrane. In spite of their small size all parts are structurally normal. The anatomical and biochemical evidence indicates that this flagellate has been placed in the wrong group. The details given include a few observations on division stages of the plastid and mitochondrion and on the growth of the flagellum. An emended diagnosis is inserted as a guide to the ultimate reclassing and renaming of the organism.

\section{REFERENCES}

BUTCHER, R. W., I952. Contributions to our knowledge of the smaller marine algae. 7. mar. biol. Ass. U.K., Vol. 31, pp. 175-91.

FAURÉ-FrÉmIET, E. \& RouILLER, C., I957. Le flagelle interne d'une Chrysomonadale: Chromulina psammobia. C.R. Acad. Sci., Paris, T. 244, pp. $2655-7$.

GREenWOOD, A. D., MANTON, I. \& ClaRKE, B., I957. Observations on the structure of the zoospores of Vaucheria. F. exp. Bot., Vol. 8, pp. 7I-86.

GreENwOOD, A. D., I959. Observations on the structure of the zoospores of Vaucheria. II. F. exp. Bot., Vol. Io, pp. 55-68.

Kennedy, G. J. \& Nicol, J. A. C., 1959. The pigments of Chaetopterus. Proc. roy. Soc. B (in the press).

Knight-Jones, E. W. \& Walne, P. R., I95I. Chromulina pusilla Butcher, a dominant member of the ultraplankton. Nature, Lond., Vol. I67, p. 445.

KNIGHT-JonES, E. W., I95I. Preliminary studies of nanoplankton and ultraplankton systematics and abundance by a quantitative culture method. F. Cons. int. Explor. Mer, Vol. 17, pp. I40-55.

Manton, I., I955. Observations with the electron microscope on Synura caroliniana Whitford. Proc. Leeds phil. lit. Soc. vol. 6, pp. 306-316.

- 1956. Observations with the electron microscope on the internal structure of the zoospore of a brown alga. F. exp. Bot., Vol. 8, pp. 294-303.

- 1957. Observations with the electron microscope on the cell structure of the antheridium and spermatozoid of Sphagnum. F. exp. Bot., Vol. 8, pp. 382-400.

MANTON, I. \& ClARKE, B., I95I. An electron microscope study of the spermatozoid of Fucus serratus. Ann. Bot., N.S., Vol. 15, pp. 46I-7I.

- 1956. Observations with the electron microscope on the internal structure of the spermatozoid of Fucus. F. exp. Bot., Vol. 7, pp. 416-32.

Manton, I., Clarke, B. \& GREENwood, A. D., I955. Observations with the electron microscope on biciliate and quadriciliate zoospores in green Algae. F. exp. Bot., Vol. 6, pp. 126-8.

Palade, G., 1952. The fine structure of mitochondria. Anat. Rec., Vol. II4, pp. 42752.

Parke, M., Manton, I. \& Clarke, B., I958. Studies on marine flagellates. IV. Morphology and microanatomy of a new species of Chrysochromulina. F. mar. biol. Ass. U.K., vol. 37, pp. 209-228. 
Parke, M. Manton, I. \& Clarke, B., 1959. Studies on marine flagellates. V. Morphology and microanatomy of Chrysochromulina strobilus sp. nov. F. mar. biol. Ass. U.K., Vol. 38,pp. 169-188.

Petersen, J. B., Caram, B. \& Hansen, J. B., I958. Observations sur les zoïdes du Chordaria flagelliformis au microscope électronique. Bot. Tidsskr., Bd. 54, pp. $57-60$.

SAGER, R. \& PALADE, G. E., 1957. Structure and development of the chloroplast in Chlamydomonas. I. The normal green cell. F. biophys. biochem. Cytol., Vol. 3, pp. $463-87$. 